\title{
FABRICATION OF COMPOSITE WICK STRUCTURE HEAT SPREADER
}

\section{Sheng-Hong Tsai}

Department of Mechanical Engineering, St. John's University, No. 499, Sec. 4, Tam-King Rd., Tamsui, Taipei 25137, Taiwan.

Yu-Tang Chen

Department of Mechanical Engineering, De Lin Institute of Technology, No. 1, Lane 380, Ching-Yun Rd., Tu-Cheng City, Taipei County 23654, Taiwan, ytang.chen@msa.hinet.net

Shung-Wen Kang

Department of Mechanical and Electro-Mechanical Engineering, Tamkang University, No. 151, Ying-Chuan Rd., Tamsui, Taipei 25137, Taiwan.

Follow this and additional works at: https://jmstt.ntou.edu.tw/journal

Part of the Engineering Commons

\section{Recommended Citation}

Tsai, Sheng-Hong; Chen, Yu-Tang; and Kang, Shung-Wen (2012) "FABRICATION OF COMPOSITE WICK STRUCTURE HEAT SPREADER," Journal of Marine Science and Technology: Vol. 20: Iss. 2, Article 6.

DOI: $10.51400 / 2709-6998.1834$

Available at: https://jmstt.ntou.edu.tw/journal/vol20/iss2/6

This Research Article is brought to you for free and open access by Journal of Marine Science and Technology. It has been accepted for inclusion in Journal of Marine Science and Technology by an authorized editor of Journal of Marine Science and Technology. 


\title{
FABRICATION OF COMPOSITE WICK STRUCTURE HEAT SPREADER
}

\author{
Sheng-Hong Tsai ${ }^{1}$, Yu-Tang $\mathrm{Chen}^{2}$, and Shung-Wen Kang ${ }^{3}$
}

Key words: heat spreader, heat sink, system thermal resistance.

\begin{abstract}
A novel heat spreader was developed with its main cavity of copper tube, where copper mesh and support structure was served as the capillary constructions. The size of the support structure was $73 \mathrm{~mm} \times 48.5 \mathrm{~mm} \times 2.7 \mathrm{~mm}$. Ceramic heater, $30 \mathrm{~mm} \times 30 \mathrm{~mm}$, was used as the heating source with the output power from 10 Watts to 130 Watts, and utilized the heat sink integrated with fan as the cooler. De-ion water was employed as the working fluid with the same filling charge. When heating power was 130 Watts, the temperature of heat source in heat spreader was lower than in copper plate about $4.3^{\circ} \mathrm{C}$.
\end{abstract}

\section{INTRODUCTION}

Over the last decade, by the developments of nanotechnology and semiconductor packaging, multiple CPU execution cores have fabricated in a single processor package. With the increasing speed and density of chips, the engineers are struggling to cool it down while facing thermal challenges in all designs. Recently, the vapor chamber (VC) was attracted very much for the electronic cooling due to the remarkable low spreading thermal resistance with very little temperature drop on the plane.

In 2005, Go [2] has investigated the thermal performance of an acetone-charged $\mathrm{VC}$ heat sink containing new micro-wick structures, the results indicated that a cost-effective metaletched micro-wick structure was proposed for CPU cooling and it also worked successfully for a high heat input of $140 \mathrm{~W}$. Yasushi et al. describes the effect of heat source size on the heat transfer characteristics of the VC. They found that the thermal resistance of the condenser section inside the $\mathrm{VC}$ was

Paper submitted 05/07/10; revised 08/26/10; accepted 10/12/10. Author for correspondence: Yu-Tang Chen (e-mail: ytang.chen@msa.hinet.net).

${ }^{I}$ Department of Mechanical Engineering, St. John's University, No. 499, Sec. 4, Tam-King Rd., Tamsui, Taipei 25137, Taiwan.

${ }^{2}$ Department of Mechanical Engineering, De Lin Institute of Technology, No. 1, Lane 380, Ching-Yun Rd., Tu-Cheng City, Taipei County 23654, Taiwan.

${ }^{3}$ Department of Mechanical and Electro-Mechanical Engineering, Tamkang University, No. 151, Ying-Chuan Rd., Tamsui, Taipei 25137, Taiwan. very small, and that of evaporator section was nearly equal to the total thermal resistance of the $\mathrm{VC}$, implying that the thermal resistance of the evaporator section was dominant inside the VC. It was also revealed that the thermal resistance of the $\mathrm{VC}$ was hardly affected by the heat flux applied from the heat source, while it increased as the heat source became smaller [7]. VC using high thermal conductivity and permeability graphite foam as a wick has investigated, and with the ethanol employed as the working fluid, the $\mathrm{VC}$ has been demonstrated at a heat flux of $80 \mathrm{~W} / \mathrm{cm}^{2}$ [6]. Wang et al. analyzed the spreading ability of rectangular plates and compared between copper/aluminum plates and a VC having the same thickness. The experimental showed the $\mathrm{VC}$ would offer a lower temperature rise and a more uniform temperature distribution [1]. In 2002, the radial grooved micro heat pipes (MHPS) with a three-layer structure were fabricated employing the bulk micro machining and eutectic bonding technology. The various fill rates were investigated in this study. For $27 \mathrm{~W}$ the highest employed fill rate of $70 \%$ showed the best performance, the evaporator temperature was $27 \%$ lower than that of the plain wafer [4]. At then the star grooves and rhombus grooves micro heat pipe were also studied. The results of rhombus grooves MHPS and star grooves MHPS have the reduction in the maximum wafer temperature were by approximately $18^{\circ} \mathrm{C}$ and $32^{\circ} \mathrm{C}$ [3]. Two kinds of capillary structures were used inside Micro heat pipe heat spreader (MHPHS), an array of $200 \mu \mathrm{m}$ wide radial grooves and threelayer 100-mesh copper screens, were researched. The test findings indicated that the groove-shaped micro heat pipe heat spreader filled with methanol at an $80 \%$ fill rate achieved better performance than any other kind of heat spreader [5].

In previous studies, the researchers have showed the advantages of heat spreader. Therefore, we try to develop a novel composite wick structure of heat spreader in present study.

\section{HEAT SPREADER MANUFACTURING}

The aim of this research was to apply the operating principle and advantages of heat pipes to liquid-vapor separation design as shown in Fig. 1. Improvements of the shearstress-caused dissipation boundary between the vapor and liquid flow and maximizing the heat pipe transfer are the major purpose in this study. Metallic copper with a relatively 


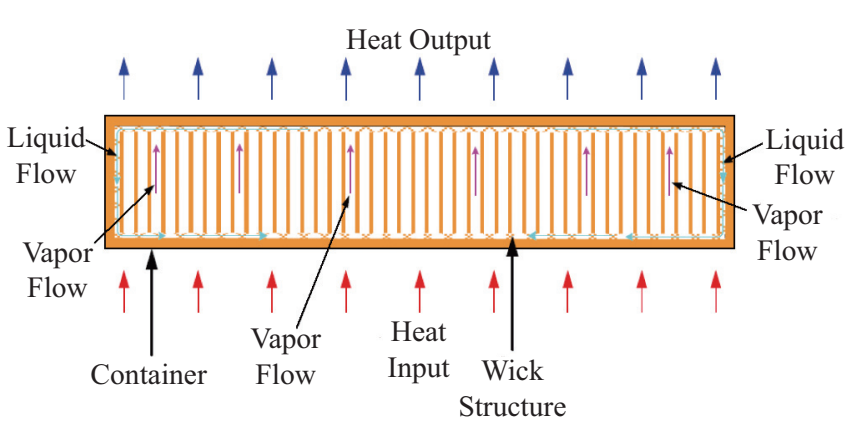

Fig. 1. A ideal operation of SSHS.

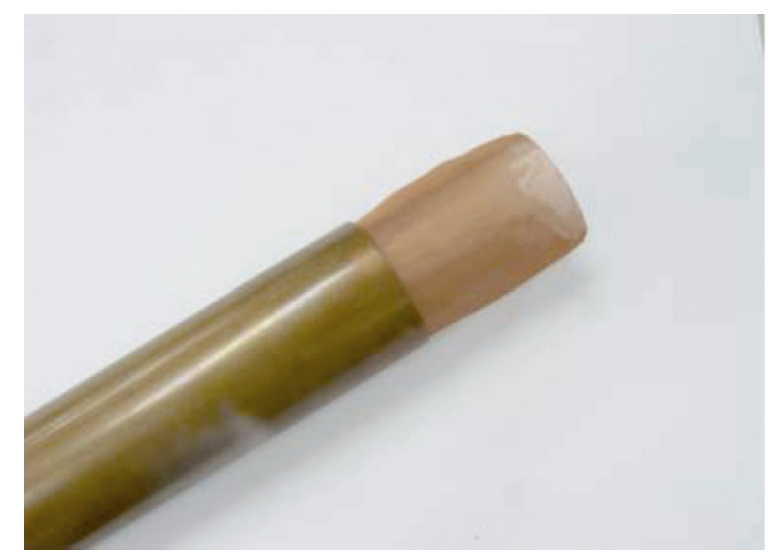

Fig. 2. The tube with 200-mesh copper screen inside.

great heat conduction coefficient was used in this research as the structural material to research and development a new type of heat spreader. In current study, the hollow flatten tube with the capillary structure always included both copper screen and support structure. The thermal performance of support structure heat spreader (SSHS) was analyzed after the evacuation, working fluid filling and packaging were finished.

\section{Design and Fabrication of SSHS Chamber}

The SSHS chamber was consisted of the oxygen-free copper tube and 200-mesh copper screen (Fig. 2). The tube with the length, outer diameter and thickness are $143 \mathrm{~mm}, 31.75 \mathrm{~mm}$ and $0.6 \mathrm{~mm}$, respectively. The 200-mesh copper screen has a wire diameter of $53 \mu \mathrm{m}$, a wire spacing of $74 \mu \mathrm{m}$ and a layer thickness of $100 \mu \mathrm{m}$. And then the tube was flattened from $31.75 \mathrm{~mm}$ to $20.56 \mathrm{~mm}$ (Fig. 3). In order to remove the oil and oxide, the clean process as following: (a) Sulfuric acid cleaning in chemical hood, (b) Remove the chemical solution by pure water, (c) the specimen was quenched and tempered at $900^{\circ} \mathrm{C}$ for forty minutes in a furnace.

\section{Design and Manufacturing of Support Structure}

The structure was comprised two rectangular copper plates ( $57 \mathrm{~mm}$ length, $43 \mathrm{~mm}$ wide, and $0.8 \mathrm{~mm}$ thickness). By using the Wire-Cut Electrical Discharge Machining (WEDM), every plate was cut with equidistant wide channels $(2 \mathrm{~mm})$ at

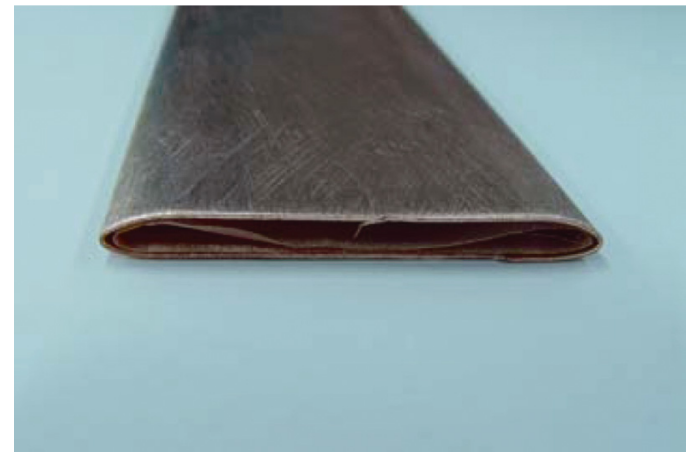

Fig. 3. The flattened tube with copper screen.

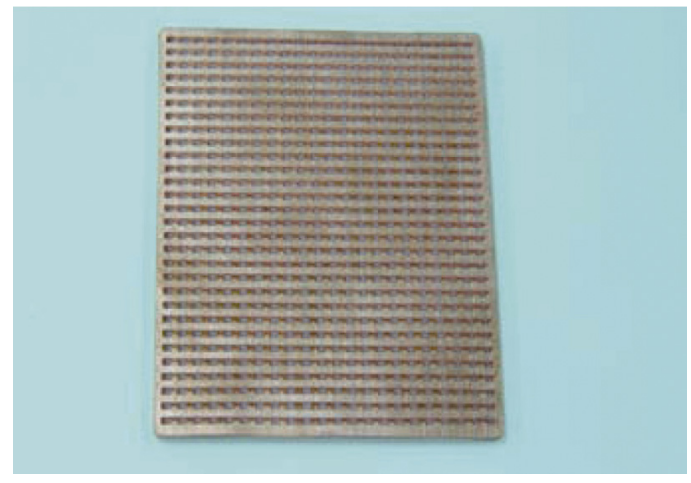

Fig. 4. The diagram of the support structure.

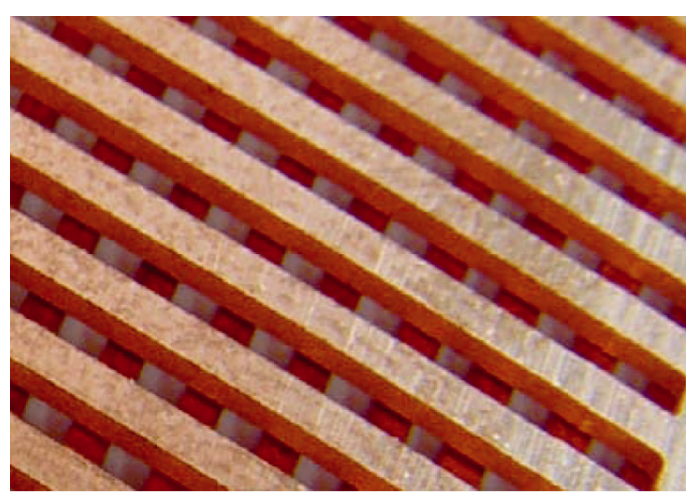

Fig. 5. The enlarged diagram of the support structure.

perpendicular direction. And then reduplicate them as shown in Figs. 4 and 5. This design makes it feasible to let the vapor flow though the hole of support structure to condensation section while the working fluid is evaporated. The support structure was stacked with screen-mesh in the chamber after the clean process.

\section{Working Fluid Evacuation, Filling and Packaging}

This research used D.I. Water as the working fluid for the SSHS. The fill charge of D.I. Water depended on capacity of wick structure and vapor channel. In present case, the fill charge was about 0.51 c.c. after calculating the dimensions of wick structure and vapor channel. 


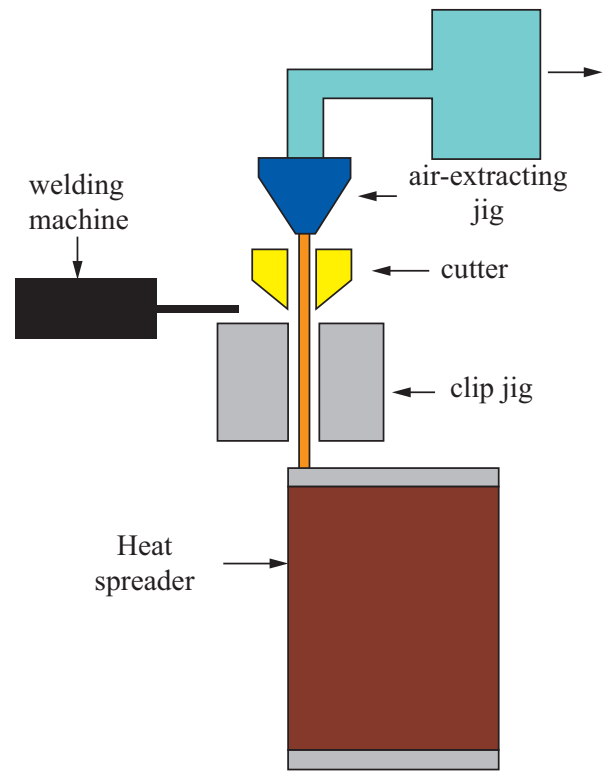

Fig. 6. The evacuation, filling and packaging processes of working fluid.

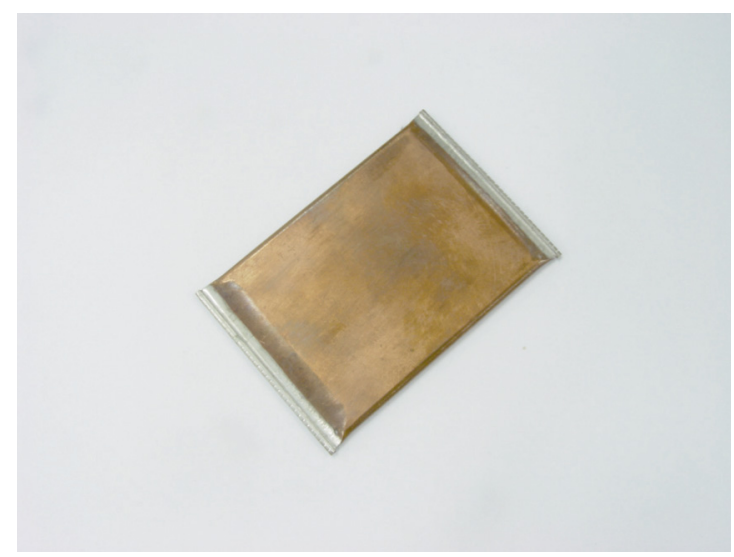

Fig. 7. The finished SSHS after packaging.

The vacuum and charging procedures was shown in Fig. 6 . First, the working fluid is charged into SSHS before the evacuation $\left(1 \times 10^{-3}\right.$ torr $)$. To avoid leakage, the filling tube was flatten by clip jig and then cut the non-useful section off. After the tube sealed, the end of device within filling tube was cut off again and sealed it. Fig. 7 showed the complete SSHS.

\section{EXPERIMENTAL SETUP AND RESULT}

Experimental evaluation of the SSHS performance was conducted with the equipments and used to measure the thermal resistance of CPU cooler as shown in Fig. 8. The CPU cooler includes fans, heat sinks and heat spreaders. During this research, both sides of the heat spreader were polished before testing. The evaporator was centrally located and positioned in the heat spreader so that it can face the hotspot surface directly. The thermal grease (SHIN ETSU X-23-7762,

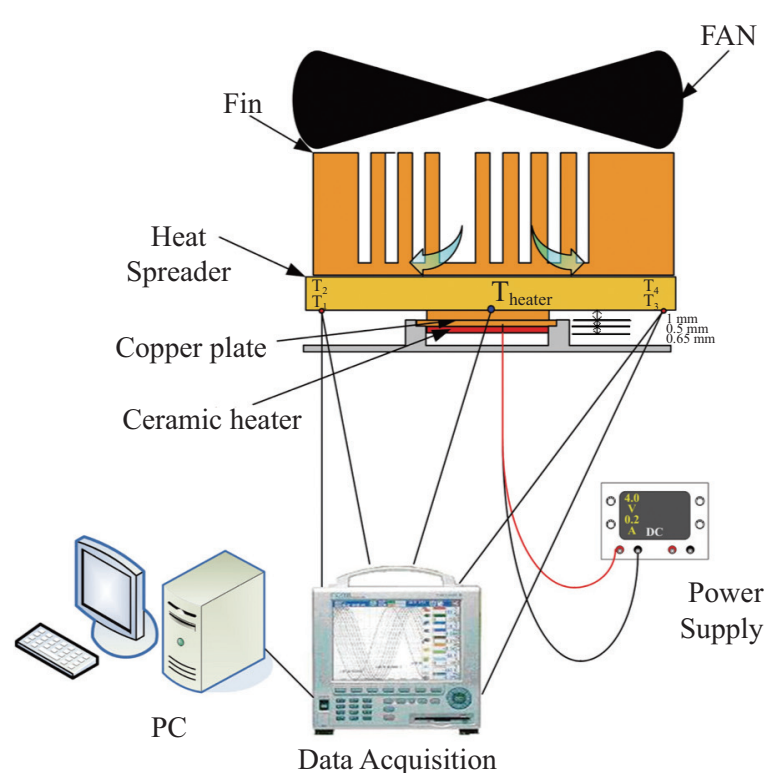

(a)

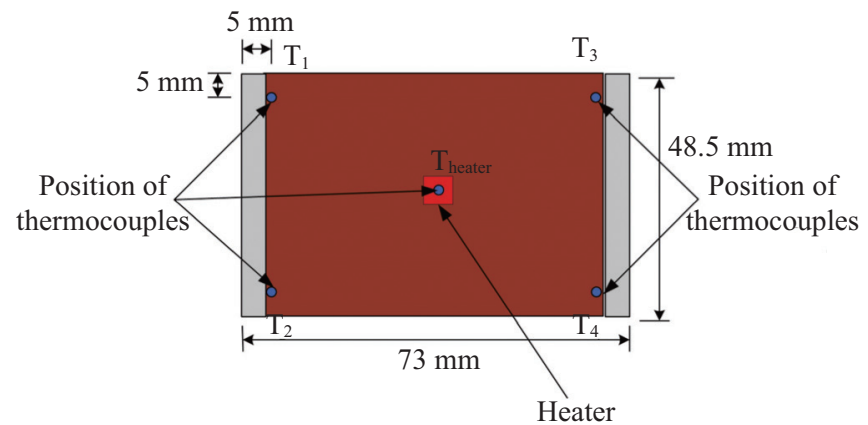

(b)

Fig. 8. (a) Schematic of the experimental setup and (b) Measuring points of temperature.

$0.9 \mathrm{~W} / \mathrm{m}-\mathrm{K}$ ) was applied on both sides of the heat spreader to reduce the contact thermal resistance between heat sink, heat spreader and ceramic heater. The fan power was set at $2.0 \mathrm{~W}$ and blew from the top to the underlying heat sink. The ambient temperature, $T_{a}$, was kept at $23 \pm 1{ }^{\circ} \mathrm{C}$ and measured on the fan entrance.

In test procedure, the power supply (GW GPC-6030D) was raised gradually and keep approximately fifteen minutes for system to achieve steady state. In different parameters, the temperature distribution $\left(T_{1}, T_{2}, T_{3}, T_{4}\right)$ along the heat spreader was measured and recorded when it's under the steady state. The local heat spreader temperature was measured by using four isolated Omega type-T thermocouples. All thermocouples were calibrated against a quartz thermometer and the uncertainty was $\pm 0.1^{\circ} \mathrm{C}$.

In present case, a copper plate with the same scale was tested to compare the thermal performance. Based on temperature distribution along heat spreader, the thermal resistances of system $\left(R_{\text {system }}\right)$ and heat spreader $\left(R_{h s}\right)$ were calculated by following equations: 


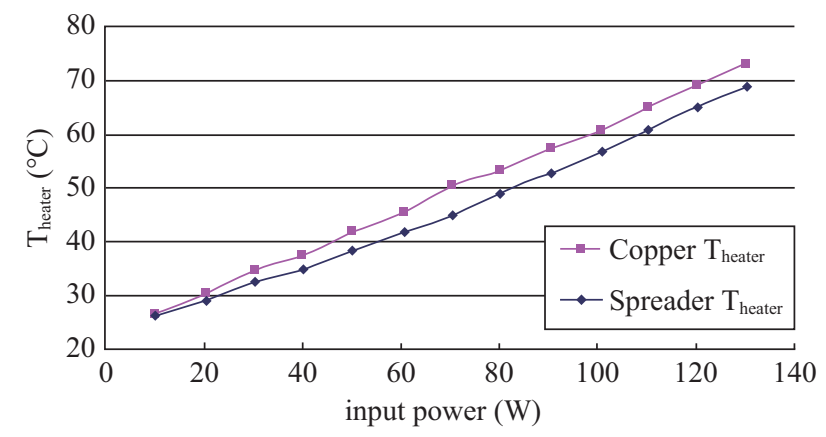

Fig. 9. The relationship between the surface temperature of heater and heating power.

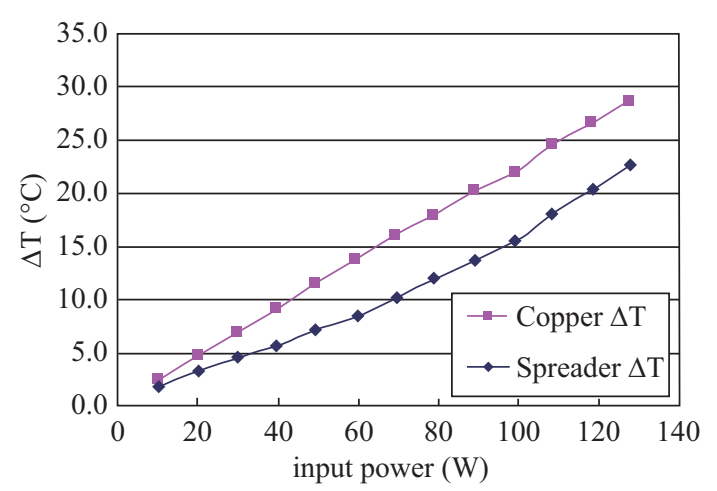

Fig. 10. The difference of temperature between copper and spreader at different power.

$$
\begin{gathered}
R_{\text {system }}=\frac{\left(T_{\text {heater }}-T_{a}\right)}{Q} \\
R_{h s}=\frac{\left(T_{\text {heater }}-T_{\text {average }}\right)}{Q}=\frac{\Delta T}{Q}
\end{gathered}
$$

Wherein,

$T_{\text {heater }}$ : the temperature of ceramic heater $\left({ }^{\circ} \mathrm{C}\right)$

$T_{a}$ : the ambient temperature $\left({ }^{\circ} \mathrm{C}\right)$

$$
T_{\text {average }}: \frac{T_{1}+T_{2}+T_{3}+T_{4}}{4}\left({ }^{\circ} \mathrm{C}\right)
$$

Fig. 9 illustrates the relationship between the surface temperature of heater and the heating power. When the input power was $128 \mathrm{~W}$, the surface temperature of heater was higher than heat spreader about $4.3^{\circ} \mathrm{C}$. It clearly shows the spreader with support structure support the lower difference of temperature under various heat loading. According to the temperature of heater and average temperature of spreader, the thermal performance was calculated as shown in Figs. 10-12, respectively. As it shows, the average surface temperature of copper plate was higher than spreader in various power levels; therefore the spreader can remove more heat and maintain lower surface temperature at high heat flux.

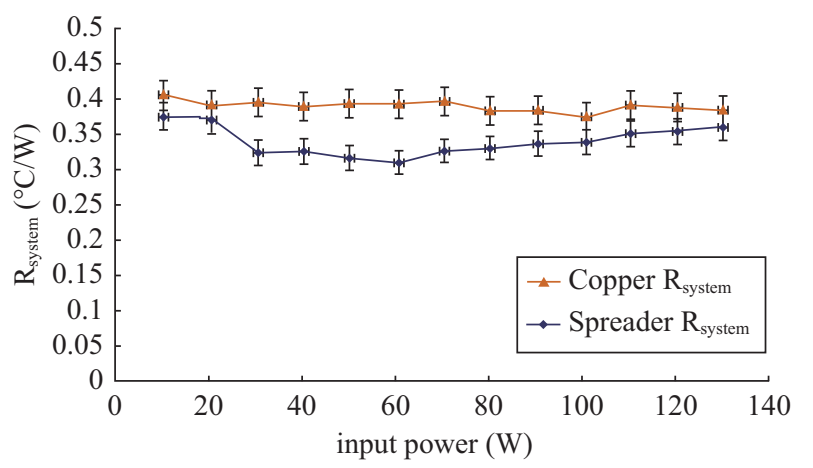

Fig. 11. The relationship between thermal resistance and input power.

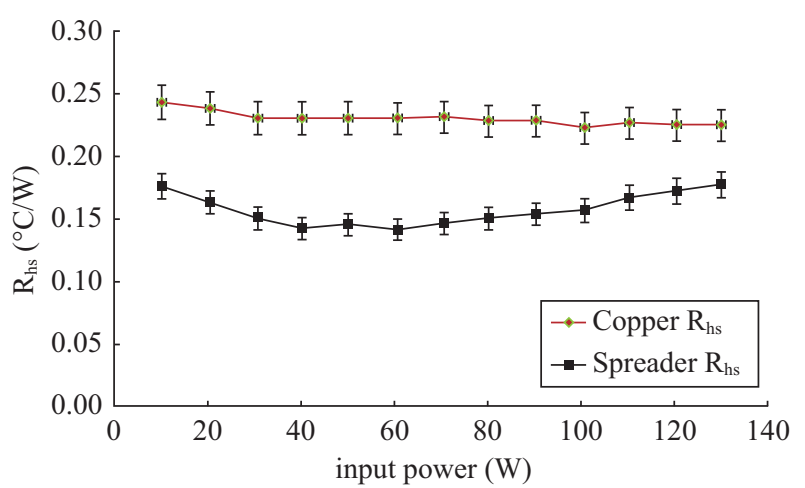

Fig. 12. The relationship between the thermal resistance of copper plate and SSHS at different input power.

A simple comparison of the performance between heat spreader and copper plate was showed in Figs. 11 and 12. Both of the system thermal resistance and spreader resistance are lower than copper plate. To understand the consistency of temperature, an IR-temperature image system (ThermaCam, SC500) was utilized to observe the surface temperature as shown in Figs. 13 and 14. In present study, the maximum surface temperature of copper plate is higher than of heat spreader about $2.2^{\circ} \mathrm{C}$ ( 8 Watts). Furthermore, the heat spreader within support structure not only removes the problem of hot spot but also make the surface temperature lower than copper at the same power.

\section{SUMMARY}

This study investigated the thermal performance of heat spreader within the support structure. A novel heat spreader was developed with its main cavity of copper tube, where the copper mesh was served as the capillary construction, the centre part was supported by a crossed structure manufactured by wire cut machine and the size of length, width and height were $73 \mathrm{~mm}, 48.5 \mathrm{~mm}$ and $2.7 \mathrm{~mm}$ respectively. In order to understand the performance of SSHP, a copper plate with the same size was also tested for comparison. The results are shown as followed. 


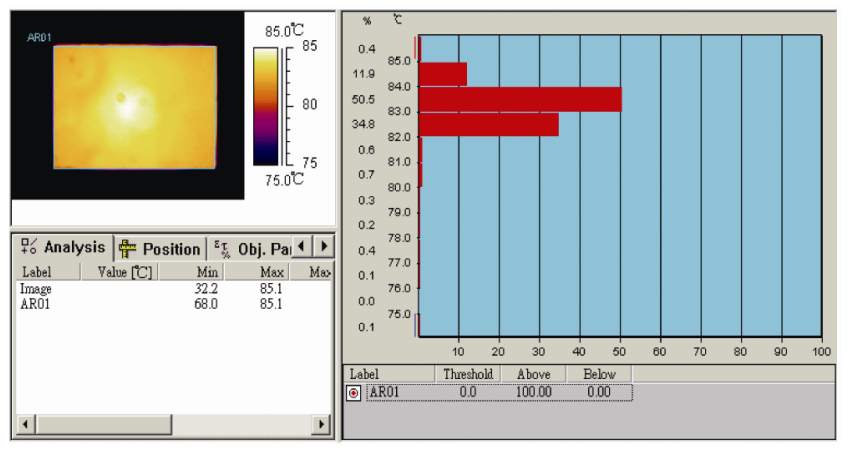

Fig. 13. The temperature distribution of copper plate by IR-temperature image system.

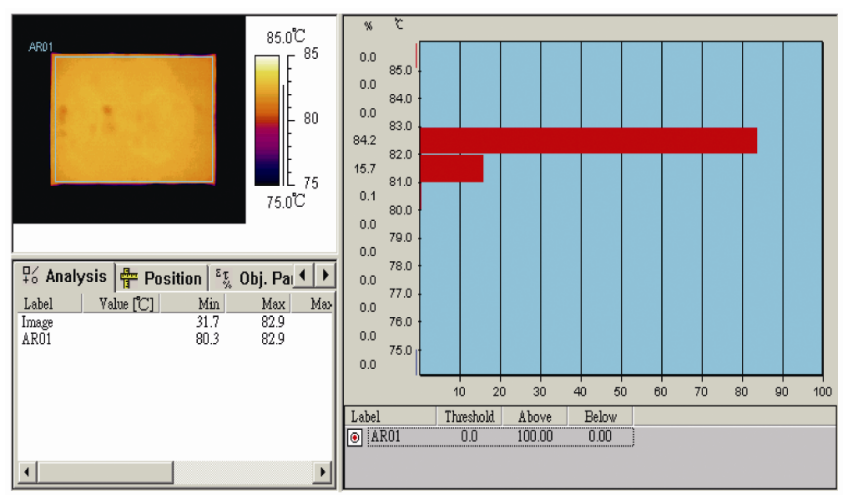

Fig. 14. The temperature distribution of intersect structure heat spreader by IR-temperature image system.

(1) When heating power was $130 \mathrm{~W}$, the heat source temperature of heat spreader was $68.8^{\circ} \mathrm{C}$ and the system thermal resistance was $0.363^{\circ} \mathrm{C} / \mathrm{W}$. Compared to a copper spreader, the heat source temperature was lowered by $4.3^{\circ} \mathrm{C}$ and the system thermal resistance was lowered for $5.7 \%$.

(2) Comparing the temperature gradient between the copper plate and SSHS at the same input power $(130 \mathrm{~W})$, the temperature gradient of SSHS is lower than copper plate about $5^{\circ} \mathrm{C}$. It means that the SSHS have a more uniform temperature distribution than copper to avoid the hot spot damage.

In this investigation, the spreader within support structure not only removes the problem of hot spot but also make the surface temperature lower than copper at the same power. Because the support structure provides the multi-dimension for liquid-flow path in heat spreader and enhances the capillary capability to avoid the phenomena of dryout causing the hot spot problem. Further studies will focus on the boiling behavior in the wick to fully understand the mechanisms.

\section{REFERENCES}

1. Chen, Y. S., Chien, K. H., Wang, C. C., Hung, T. C., Ferng, Y. M., and Pei, B. S., "Investigations of the thermal spreading effects of rectangular conduction plates and vapor chamber," Journal of Electronic Packaging, Vol. 129, No. 3, pp. 348-355 (2007).

2. Go, J. S., "Quantitative thermal performance evaluation of a cost-effective vapor chamber heat sink containing a metal-etched microwick structure for advanced microprocessor cooling," Sensors and Actuators A, Vol. 121, pp. 549-556 (2005).

3. Kang, S. W. and Huang, D., "Fabrication of star grooves and rhombus grooves micro heat pipe," Journal of Micromechanics and Microengineering, Vol. 12, No. 5, pp. 525-531 (2002).

4. Kang, S. W., Tsai, S. H., and Chen, H. C., "Fabrication and test of radial grooved micro heat pipes," Applied Thermal Engineering, Vol. 22, No. 14, pp. 1559-1568 (2002).

5. Kang, S. W., Tsai, S. H., and Ko, M. H., "Metallic micro heat pipe heat spreader fabrication," Applied Thermal Engineering, Vol. 24, No. 2-3, pp. 299-309 (2004).

6. Lu, M., Mok, L., and Bezama, R. J., "A graphite foams based vapor chamber for chip heat spreading," Journal of Electronic Packaging, Vol. 128, No. 4, pp. 427-431 (2006).

7. Yasushi, K., Hideaki, I., Masataka, M., Yuji, S., and Shuici, T., "Fundamental experiments and numerical analyses on heat transfer characteristics of a vapor chamber (Effect of heat source size)," JSME International Journal B, Vol. 49, No. 4, pp. 1233-1240 (2006). 